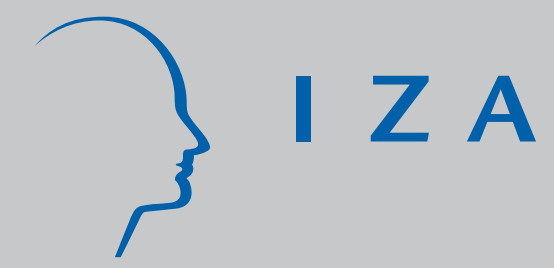

IZA DP No. 1250

Observable and Unobservable Household Sharing Rules: Evidence from Young

Couples' Pocket Money

J ungmin Lee

August 2004 


\title{
Observable and Unobservable Household Sharing Rules: Evidence from Young Couples' Pocket Money
}

\author{
Jungmin Lee \\ University of Arkansas-Fayetteville \\ and IZA Bonn
}
Discussion Paper No. 1250
August 2004

\author{
IZA \\ P.O. Box 7240 \\ 53072 Bonn \\ Germany \\ Phone: +49-228-3894-0 \\ Fax: +49-228-3894-180 \\ Email: iza@iza.org
}

\begin{abstract}
Any opinions expressed here are those of the author(s) and not those of the institute. Research disseminated by IZA may include views on policy, but the institute itself takes no institutional policy positions.

The Institute for the Study of Labor (IZA) in Bonn is a local and virtual international research center and a place of communication between science, politics and business. IZA is an independent nonprofit company supported by Deutsche Post World Net. The center is associated with the University of Bonn and offers a stimulating research environment through its research networks, research support, and visitors and doctoral programs. IZA engages in (i) original and internationally competitive research in all fields of labor economics, (ii) development of policy concepts, and (iii) dissemination of research results and concepts to the interested public.
\end{abstract}

IZA Discussion Papers often represent preliminary work and are circulated to encourage discussion. Citation of such a paper should account for its provisional character. A revised version may be available directly from the author. 
IZA Discussion Paper No. 1250

August 2004

\section{ABSTRACT}

\section{Observable and Unobservable Household Sharing Rules: Evidence from Young Couples' Pocket Money*}

The leading evidence against the unitary household models is that "who gets what" is significantly dependent upon "who earns how much." However, it is difficult to pin down the causal effect of relative earnings on intra-household resource allocation because households jointly decide both labor supply and consumption. I utilize longitudinal data to analyze the spouse's individual budgets - "pocket money." This unique data set allows for the specification of the simultaneous process of household decision-making in a fully stochastic fashion. By doing this, it is possible to differentiate unobserved spousal bargaining power from heterogeneity at the household level. The results imply that the balance of power between spouses is stable over time and robust to transitory changes in relative earnings. Public policies targeting the disadvantaged within households should be designed and implemented on the long-term basis.

JEL Classification: D1, J1

Keywords: intrahousehold resource allocation, collective household models, bargaining power

Jungmin Lee

Department of Economics

University of Arkansas-Fayetteville

Austin, TX 78712

USA

Email: JLee@walton.uark.edu

\footnotetext{
* I would like to thank Stephen Bronars, Pierre-André Chiappori, Stephen Donald, Li Gan, Dan Hamermesh, Stephen Lich-Tyler, Gerald Oettinger, Daniel Slesnick, Steve Trejo, and seminar participants at the University of Texas-Austin and the University of Arkansas-Fayetteville.
} 


\section{Introduction}

In the past two decades, no single economic theory has been more challenged than the unitary household model. The leading evidence against it is a universal rejection of the income-pooling hypothesis. Existing empirical investigations have found that "where to spend how much" is significantly dependent upon "who earns how much." ${ }^{1}$ The underlying assumption is that individual family members have different and conflicting preferences. Intra-household resource allocation is therefore determined through a decision-making process that aggregates individual preferences in a certain way.

A lot of variables have been used as indicators of bargaining power. Among others, a single family member's income or "relative earnings" would seem to be a legitimate measure of his or her power to control family resources and thereby to assert his or her preferences in household expenditures. However, it is hard to pin down the causal effects of relative income or earnings on intra-household resource allocation, because the individual's labor market activities are also determined by the same household decision-making process that governs resource allocation.

There are at least three cases that show the endogeneity is not ignorable. First, when spouses know that the household decision-making process is highly influenced by relative earnings, there appears to be an incentive for each to participate in the labor force, to work longer, and to earn more. ${ }^{2}$ Relative earnings are, in this aspect, an outcome of strategic interactions between household members. Second, sorting individuals into households is a systematic matching process based on their preferences, in particular preferences for their relative position or bargaining power within the households. ${ }^{3}$ As a result, subsequent decisions such as division of labor and consumption are correlated with the initial matching

\footnotetext{
${ }^{1}$ See, among others, Thomas (1990), Phipps and Burton (1992), Browning, Borguignon, Chiappori, and Lechene (1993), Kanbur and Haddad (1994), Lundberg, Pollak, and Wales (1997), Attanasio and Lechene (2002), and Ward-Batts (2003).

${ }^{2}$ Browning, Borguignon, Chiappori, and Lechene (1993) regard this issue as a most important area of future research.

${ }^{3}$ Lundberg (1988) shows that individual work choices should be conditioned on the spouse's permanent characteristics, which were selected at the moment of marriage. Jacobsen and Rayack (1996) also show that there exists a sorting into "traditional" single-earner marriage or dual-earner marriage.
} 
based on preferences for spouse types in the marriage market. Third and more relevant to developing countries, both intrahousehold division of labor and resource allocation are endogenously determined in the social and cultural contexts. In many developing countries, husbands would depress their wife's labor market activity for non-economic reasons, and as a result the wife's choices about work and earnings reflect the underlying balance of power between the spouses. ${ }^{4}$ As such, a simple correlation between relative earnings and household consumption patterns does not allow us to test for unitary models. We can observe, for example, a negative correlation between the wife's relative earnings and household consumption of the husband's favorite items, such as alcohol and tobacco, but this might be a result of unobservable heterogeneity in household preferences and balance of power. The above examples clearly demonstrate that while bringing money into the household yields a sense of entitlement or power to decide the way it is spent, the household decision-making process determines who earns in the money in the first place.

As a result, relative earnings should be treated as endogenous in household consumption. The endogeneity problem of relative earnings has been dealt with in one way or another in the literature. Unearned income has often been used as an alternative (McElroy and Horney 1981, Thomas 1990, Schultz 1990). However, it seems to be not entirely exogenous since unearned income and assets are also possibly an accumulated outcome of the inter-temporal household allocation process (Lundberg and Pollak 1996). Some studies restricted samples to couples in which both spouses work full-time (Browning, Bourguignon, Chiappori, and Lechene 1993), but they had to assume that the selection into this specific group is random for household consumption decisions, which seems questionable. ${ }^{5}$ Other observable characteristics have also been used: for example, between-spouse differences in age, education, and premarital asset holdings. However, they are also endogenous since

\footnotetext{
${ }^{4}$ According to Basu (2001) it is called the "conservative" case in which "a man considers his pride hurt if his wife goes out to work." On the contrary, Browning, Borguignon, Chiappori, and Lechene (1993) point out the possibility that "an unobservable increase in bargaining power for one partner may lead to a decrease in income since income is not now so important for maintaining a bargaining position."

${ }^{5}$ Exogenous variation in spousal relative income is necessary to determine the causality. Lundberg, Pollak, and Wales (1997) and Ward-Batts (2003) exploit exogenous income transfer between spouses incurred by the child benefit policy change in the U.K. They reject the income-pooling hypothesis.
} 
marriage is a matching between two persons mainly based on those characteristics and a specific set of pairwise characteristics is endogenously chosen by a couple.

This study makes two primary contributions to the research. First, I utilize longitudinal data on household consumption, which allow us to develop a fully stochastic model of the household decision-making process in which unobservable family-specific effects and time-invariant bargaining structures are controlled for. In doing so I can, at least partially, resolve the endogeneity problem of relative earnings by allowing for unobserved heterogeneity of an individual's long-run earning power, which is omitted in cross-sectional regressions. Furthermore, this particular structure of the model enables us to separate out the effects of unobservable bargaining power, or at least its partial effects, from general heterogeneity among households. Also the time span of the data allows me to exploit a randomized redistribution of earnings across and within households due to a financial crisis in which spouses' relative earnings changed exogenously.

The results are freed of the so-called "assignability" problem, pointed out by Chiappori (1992) and Lundberg and Pollak (1996) among others, by using a direct measure of the individual's budget-pocket money. Pocket money seems more appropriate as an assignable good than any other item, such as clothing, because it is not likely to be jointly consumed. In Korea, for example, pocket money is institutionally considered as the portion of household budget that each individual member can freely spend for his or her own purposes. Household expenditures on items such as clothing, food, and housing are usually not included in pocket-money expenditures. Thus problems, like joint consumption and interdependent preferences, can be minimized when we try to infer the underlying household decision-making process from observed pocket-money expenditures. ${ }^{6}$

I find that, for the sample of young South Korean couples, unobserved heterogeneity at both the spouse and household levels plays a significant role in determining intrahousehold resource allocation, as well as individual members' labor market activities. While increasing labor force involvement and the earning power of the wife accompanies

\footnotetext{
${ }^{6}$ Another advantage of using pocket money to indicate personal consumption is that it tends to be less lumpy than, for example, expenditures on clothing even though it might fluctuate slightly day by day. Pocket money is not for the expenditure on durables; rather, it is used directly for nondurable consumption.
} 
resource reallocation toward women, the favorable effects are not economically significant. This paper suggests that any exogenous income transfer favorable to the wife, especially when it is a temporary or one-time measure, would not improve her welfare as much as intended without shaking the underlying intra-household balance of power. Interestingly, a general improvement of the family's economic status has negative impacts on intrahousehold inequality. In addition, I find that spouses preferences differ significantly over certain goods, such as education and clothing, while they differ minimally for other goods like housing and utilities. In summary, my findings suggest that the balance of power between spouses is stable over time and robust to transitory changes in relative earnings.

\section{Conceptual Model and Empirical Strategy}

\subsection{Recovering Household Sharing Rules with Exogenous Earnings}

Consider a household with two members, $i=h, w$, each of whose preferences are defined over his or her pocket money, $C_{i}$, and an $L$-vector of other private consumption goods, $C_{i, l}, l=1, \cdots, L .^{7}$ In other words, the utility function is egoistic, $U_{i}=$ $U_{i}\left(C_{i}, C_{i, 1}, \cdots, C_{i, L}\right)$. I assume that both members care for each other (Becker 1991), so that their actual utility is given by $W_{i}$,

$$
W_{i}\left[U_{h}, U_{w}\right]
$$

for $i=h, w$. These utility functions impose a weak separability between a person's own private goods and the spouse's. Temporarily I assume that labor supply is fixed and that earnings are exogenous. Under the efficiency assumption the household allocates resources to achieve a consumption plan on the Pareto frontier by maximizing the following "social welfare" function, ${ }^{8}$

\footnotetext{
${ }^{7}$ There is no public consumption in the model. It is only valid under the separability assumption that household sharing rules and individual consumption are independent of the choice of public goods. Therefore each individual's marginal rate of substitution between private goods does not depend on the level of public consumption.

${ }^{8}$ Pareto efficiency assumption is reasonable since spouses have a long-term and stable relationship (Chiappori 1988). This assumption seems valid in the context of Korea where divorce rate is, even though
} 


$$
\mu W_{h}\left[U_{h}, U_{w}\right]+(1-\mu) W_{w}\left[U_{h}, U_{w}\right]
$$

subject to the household budget constraint,

$$
\left(C_{h}+C_{w}\right)+\sum_{l=1}^{L}\left(C_{h, l}+C_{w, l}\right) \leq y_{h}+y_{w} .
$$

I assume that there is no unearned income. ${ }^{9}$ A solution to the above problem corresponds to a specific value of $\mu$, which is interpreted as the "weight" given to the member $h$ in the aggregated household welfare function. An interpretation of the parameter $\mu$ is a "distribution of power" function (Browning and Chiappori 1998). Its value and functional form are known to members, but unknown to the econometrician. Indeed testing for the existence of $\mu$ and recovering its relationships to measurable and unmeasurable characteristics, such as the spousal earnings gap, are of principal interest in this paper. Temporarily I assume that $\mu$ is solely dependent on $\theta$, spousal relative earnings,

$$
\mu=\mu(\theta)=\mu\left(\frac{y_{w}}{y_{h}+y_{w}}\right) .
$$

Relative earnings are specifically defined as the wife's contribution to total household earnings. Chiappori (1992) and Bourguignon, Browning, Chiappori, and Lechene (1993) show that there exists a specific sharing rule for the full income that corresponds to each value of $\mu$ and gives us the same solution as that of the original household problem represented by (2) and (3). It is a well-known two-stage budgeting process; first, the full income is divided between spouses, and then each spouse separately chooses a consumption bundle subject to the corresponding budget constraint. The idea here is analogous to the second welfare theorem, which implies the redistribution of resources to achieve a Paretoefficient outcome. Representing the solution for pocket money in terms of the sharing rule, and with interior solutions assumed, we have:

recently rising, by far lower than the U.S.

${ }^{9}$ This paper focuses on young couples for whom unearned income is relatively unimportant in their financial resource, which provides an empirical rationale for the assumption. 


$$
\begin{aligned}
& C_{h}=f_{h}(Y, \mu(\theta))=f_{h}\left(\phi\left(y_{h}+y_{w}, \theta\right)\right) \\
& C_{w}=f_{w}(Y, \mu(\theta))=f_{w}\left(Y-\phi\left(y_{h}+y_{w}, \theta\right)\right),
\end{aligned}
$$

where $\phi$ is the husband's share of the total income. Spouses have different consumption functions because they have different preferences. For example, marginal propensity to consume is, in general, different between spouses. Note that the spouse's pocket money depends on his/her earnings not only through the total household income, $Y=y_{h}+y_{w}$, but also through the sharing rule, $\phi$. The particular structure of consumption functions provides testable restrictions and allows us to recover the partials of the sharing rule, $\frac{\partial \phi}{\partial Y}$ and $\frac{\partial \phi}{\partial \theta}$. The partial derivatives of individual consumption with respect to $y_{h}$ and $y_{w}$ are:

$$
\begin{aligned}
\alpha_{h} & =\frac{\partial C_{h}}{\partial y_{h}}=\frac{\partial f_{h}}{\partial \phi} \cdot\left(\frac{\partial \phi}{\partial Y}+\frac{\partial \phi}{\partial \theta} \cdot \frac{\partial \theta}{\partial y_{h}}\right), \\
\beta_{h} & =\frac{\partial C_{h}}{\partial y_{w}}=\frac{\partial f_{h}}{\partial \phi} \cdot\left(\frac{\partial \phi}{\partial Y}+\frac{\partial \phi}{\partial \theta} \cdot \frac{\partial \theta}{\partial y_{w}}\right), \\
\alpha_{w} & =\frac{\partial C_{w}}{\partial y_{h}}=f_{w}^{\prime}(\cdot) \cdot\left(1-\left(\frac{\partial \phi}{\partial Y}+\frac{\partial \phi}{\partial \theta} \cdot \frac{\partial \theta}{\partial y_{h}}\right)\right), \\
\beta_{w} & =\frac{\partial C_{w}}{\partial y_{w}}=f_{w}^{\prime}(\cdot) \cdot\left(1-\left(\frac{\partial \phi}{\partial Y}+\frac{\partial \phi}{\partial \theta} \cdot \frac{\partial \theta}{\partial y_{w}}\right)\right) .
\end{aligned}
$$

Clearly, the income-pooling hypothesis does not generally hold in this model since individual earnings change the sharing rule through the earnings share, $\theta$. The incomepooling hypothesis indicates that $\alpha_{h}=\beta_{h}$ and $\alpha_{w}=\beta_{w}$, which is surely testable. Taking ratios of the partial derivatives leads to:

$$
\begin{aligned}
\frac{\alpha_{h}}{\beta_{h}} & =\frac{\partial C_{h} / \partial y_{h}}{\partial C_{h} / \partial y_{w}}=\frac{A}{B}, \\
\frac{\alpha_{w}}{\beta_{w}} & =\frac{\partial C_{w} / \partial y_{h}}{\partial C_{w} / \partial y_{w}}=\frac{1-A}{1-B},
\end{aligned}
$$

where $A=\left(\frac{\partial \phi}{\partial Y}+\frac{\partial \phi}{\partial \theta} \frac{\partial \theta}{\partial y_{h}}\right)$ and $B=\left(\frac{\partial \phi}{\partial Y}+\frac{\partial \phi}{\partial \theta} \frac{\partial \theta}{\partial y_{w}}\right)$. Therefore with information on the partial derivatives, straightforward calculations recover the sharing rule up to an additive constant. 


$$
\begin{gathered}
\frac{\partial \phi}{\partial \theta}=\frac{1}{Y} \cdot(B-A) \leq 0 . \\
\frac{\partial \phi}{\partial Y}=A+\frac{\partial \phi}{\partial \theta} \cdot \frac{y_{w}}{Y^{2}}=B-\frac{\partial \phi}{\partial \theta} \cdot \frac{y_{h}}{Y^{2}} .
\end{gathered}
$$

Since an increase in the full income would increase both spouses' budget with the earnings ratio held constant, the result implies another inequality,

$$
0 \leq \frac{\partial \phi}{\partial Y} \leq 1
$$

Recovering $\partial \phi / \partial \theta$ is important as it measures the marginal effect of a distribution factor on the individual's share of resources. Its significance and magnitude indicate how individual members' preferences are different and sometimes even conflicting, and how households aggregate these preferences. The meaning of $\partial \phi / \partial Y$ is also interesting; if it equals 0.5 , then it implies that households would split equally any additional amount of family income between the spouses. The partial derivative measures the marginal effect of general family income on intra-household sharing inequality.

\subsection{Allowing for Unobserved Bargaining Power}

There is a major shortcoming in the above model; the assumption of exogenous earnings. Suppose that we estimate the effect of relative earnings on the household sharing rule in equation (8). Note that the model assumes exogenous earnings; we can identify the sharing rule only if we can consistently estimate the marginal effects of earnings on individual consumption. However, it is very doubtful that earnings are exogenous in the household decisions.

I attempts to solve the endogeneity problem by allowing for unobserved heterogeneity across individuals and households. ${ }^{10}$ In doing so, I deal with the possibility that there is a comprehensive framework which determines both relative earnings and resource allocation

\footnotetext{
${ }^{10}$ There are at least three other approaches. First, we can use instrumental-variable estimation methods. However it is difficult to find appropriate instrument for earnings. Second, although complicated, it is possible to model labor supply decisions explicitly together with intra-household allocation decisions. Third, if possible, we can exploit exogenous variation in earnings due to a natural experiment. Other than
} 
within households. My approach will work well particularly in the context of developing countries where gender roles are firmly rooted and both the division of labor and resource allocation within households are embedded in the cultural and social contexts (Basu 2002, Lundberg and Pollak 1993). Individuals and households have different preferences in unmeasurable ways, and how those differences are resolved hinges on the social context (Rasul 2003, Lundberg and Pollak 1996). To account for the above aspect, I allow spousespecific welfare weights to depend on unobserved bargaining power as well, therefore:

$$
\mu=\mu(\theta, \tilde{\theta})
$$

where $\tilde{\theta}$ represents a measure of unobservable bargaining power. Specifically it represents the wife's relative power within the household, which is different across households in unmeasured ways. For example, this might stand for the degree to which a couple conforms to the social norm about gender roles. As such $\tilde{\theta}$ is likely to be positively correlated with $\theta$, because unobserved bargaining power may determine the wife's commitment to housework and her choice whether to work at home or in the market.

Now suppose that we estimate the following equation:

$$
C_{i f t}=\alpha_{i} y_{h f t}+\beta_{i} y_{w f t}+X_{f t} \gamma_{i}+T_{i t}+u_{i f t},
$$

where $i=h, w$ and $C_{i f t}$ is the natural logarithm of average monthly pocket money of family member $i$ in household $f$ at year $t$. $y_{i f t}$ is monthly earnings and $X_{f t}$ is a vector of time-varying or time-invariant family and spouse characteristics. A set of dummy variables, $T_{i t}$, represents spouse-specific time trends. ${ }^{11}$

The novelty of the above specifications resides in allowing for unobservable heterogeneity in a comprehensive way. The unobserved term in equation (11) is decomposed into three parts,

exploiting longitudinal structure of the data, this paper also exploits exogenous earnings changes due to macroeconomic shock during the Asian financial crisis.

${ }^{11}$ Working hours are not included because they have, if any, only negligible effects. Including an indicator for women's labor force participation (an indicator for women with zero earnings) does not make any difference either. Nonlinear specifications of individual earnings do not change the results. 


$$
u_{i f t}=F_{f}+\Theta_{i f}(\tilde{\theta})+\epsilon_{i f t},
$$

where $\epsilon_{\text {ift }}$ is assumed to be independently and identically distributed across families and spouses. I allow for heterogeneity at two levels; first, $F_{f}$ represents a family-specific fixed effect, which is supposed to capture any omitted or unobservable time-constant family common characteristic. This is likely to demonstrate the correlation between spousal independence and his or her pocket money allocation. As spouses are more "individualistic," personal expenses generally increase for both spouses. ${ }^{12}$

Second and more important, equation (12) allows for spouse-specific fixed effects, $\Theta_{i f}$. Since I define $\tilde{\theta}$ as the unobserved bargaining power of wives, we have that $\partial \Theta_{h f} / \partial \tilde{\theta}<0$ and $\partial \Theta_{w f} / \partial \tilde{\theta}>0$. The fixed effects may pick up any omitted or unobservable determinant specific to spouse $i$ of household $f$ - anything that increases his or her pocket money, but is not necessarily observable to econometricians. If bargaining power is not fully observed, and if the unobserved factor of bargaining power is almost invariant over time, then this may be captured by this term. It seems a strong assumption that unobserved bargaining power is invariant over time; but it does not seem unreasonable, since the timevarying portion of bargaining power is explained by time-varying observable variables. Furthermore, as mentioned before, the rationale for unobservable bargaining power is that the household decision-making processes regarding resource allocation as well as the division of labor are determined by spouses' preferences for bargaining power, which are likely initialized by the social norm about gender roles. The social convention tends to be stable over time.

By allowing for unobservable bargaining power, I attempt to develop a fully stochastic specification of the "distribution of power" function (Browning and Chiappori 1998) or a stochastic specification of "threat points" in the separate spheres bargaining model (Lundberg and Pollak 1993). Without controlling for unobservable heterogeneity, simple ordinary least squares (OLS) estimates of $\alpha_{h}, \beta_{h}, \alpha_{w}$, and $\beta_{w}$, are biased because spousal

\footnotetext{
${ }^{12}$ In the sample, spouses' pocket money is significantly positively correlated with each other, which provides an empirical rationale for including family-specific fixed effects. Spearman's test for independence between spouses is rejected at any significance level $(p$-value $<.01)$.
} 
earnings and pocket money may well be commonly linked to the third factor - unobserved bargaining power. ${ }^{13}$

Having longitudinal data allows us to remove unobservable heterogeneity and consistently estimate equation (11). This is achieved by the fixed effects (FE) estimation procedure. Formally, the FE specification is:

$$
\ddot{C}_{i f t}=\alpha_{i} \ddot{y}_{h f t}+\beta_{i} \ddot{y}_{w f t}+\ddot{X}_{f t} \gamma_{i}+\ddot{\epsilon}_{i f t}
$$

where double dots over the variables denote a within-transformation. The FE estimation is necessary and sufficient for researchers who are only interested in consistently identifying the effects of observable characteristics, such as earnings, on intra-household allocation. Notice that the FE estimation removes any omitted or unobservable time-constant errors, both family-specific heterogeneity and unobserved bargaining power.

On the other hand, we cannot distinguish unobservable bargaining power from familyspecific heterogeneity. The distinction is important because they have completely different meanings in household decision process. Fortunately, identifying unobservable bargaining power can be achieved by comparing the differences between the spouses. Let us take the difference on the basic equation between spouses, following Browning, Bourguignon, Chiappori, and Lechene (1993), who called the resulting specification the "log difference equation." Specifically, we subtract the equation for wives from that for husbands:

$$
\Delta C_{f t}=\Delta \alpha y_{h f t}+\Delta \beta y_{w f t}+X_{f t} \Delta \gamma+\Delta \Theta_{f}(\tilde{\theta})+\Delta \epsilon_{f t}
$$

where $\Delta$ represents the difference between spouses. That is, $\Delta C_{f t}=C_{h f t}-C_{w f t}, \Delta \alpha=$ $\alpha_{h}-\alpha_{w}, \ldots$, and $\Delta \Theta_{f}(\tilde{\theta})=\Theta_{h f}(\tilde{\theta})-\Theta_{w f}(\tilde{\theta})$. Furthermore $\partial \Delta \Theta_{f} / \partial \tilde{\theta}<0$ by assumption. In equation (14) the family-specific fixed effect, $F_{f}$, is removed and there remains only unobservable bargaining power in time-constant fixed effects. ${ }^{14}$ We can consistently estimate equation (15) by transforming variables into deviations from individual and family

\footnotetext{
${ }^{13}$ In technical terms, there exists a prior agreement in which households' decisions on spousal earnings and expenditure are determined by social norms and gender roles (Lundberg and Pollak 1996).

${ }^{14}$ I only allow for time-constant family-specific effects in the specification, but the between-spouse difference technique actually removes any time-varying family-specific effects.
} 
means.

$$
\Delta \ddot{C}_{f t}=\Delta \alpha \ddot{y}_{h f t}+\Delta \beta \ddot{y}_{w f t}+\ddot{X}_{f t} \Delta \gamma+\Delta \ddot{\epsilon}_{f t} .
$$

Due to the existence of $\Delta \Theta_{f}(\tilde{\theta})$, the OLS estimates in equation (14) would be biased. Therefore any difference in estimates between equation (14) and (15) should be ascribed to the correlation between explanatory variables and unobservable bargaining power.

It is important to note that all the explanatory variables, in particular $y_{i f t}$, are potentially endogenous. The distribution of earnings within the household may be correlated with the unobserved bargaining power structure. Other spousal and family characteristics may be also endogenous. For example, the number of children may be correlated with the bargaining power relationship between the spouses. We expect that strong female power should lower fertility if other things are equal. Residential choice in metropolitan areas may also be correlated with women's relative power (Costa and Kahn 2000). It is interesting to see the effects of unobserved bargaining power on these variables. ${ }^{15}$

\section{Basic Regression Results}

\subsection{Data Source and Descriptive Statistics}

The data used in this study are the Korean Household Panel Study (KHPS). The KHPS is the first panel survey on Korean households, conducted by Daewoo Research Institute, and patterned after the PSID in the U.S. The data are available for the period between 1993 and 1998. Our sample spans the last four-year period over which information on pocket money is available, from 1995 to 1998. To ensure the homogeneity of sample, I drop observations if spouses are living separately, household heads are female, or husbands are not working. I also restrict the sample to young households in which the wife is younger

\footnotetext{
${ }^{15}$ Even age and education may be endogenous in the sense that marriage is determined according to the partners' preferences for power relations in the family. For example, when household bargaining is highly dependent on spousal age gap, those who prefer to be dominant in spousal relationships tend to look for younger partners. However, since the empirical strategies employed in this paper exploit transitory changes in variables, the coefficients on time-constant variables cannot be consistently estimated.
} 
than 41 in 1995. There are two intuitive reasons for this; first, age-group cohorts are very different in Korea's rapidly changing society in both measurable and unmeasurable ways and; second, earnings are presumably the most important source of household income for these young couples. This is helpful for the purpose of this paper to examine whether relative earnings are a reasonable indicator of bargaining power. On the other hand, intrahousehold allocation for old couples would be affected by many complicating factors other than their earnings, such as unearned financial incomes and supportive transfers from adult children. Lastly, observations are deleted if there is any missing value for crucial variables. The final sample is an unbalanced panel, consisting of 4,611 observations on 1,393 couples over 4 years.

TABLE 1 shows the descriptive statistics of the crucial variables in each year. Since the data for Korea are likely to be unfamiliar to most readers, I examine the descriptive statistics for the major variables to check for consistency with other national statistics from various sources. Average monthly household earnings are roughly 1.83 million Korean won in 1995, 2.24 in 1997, 1.90 in 1998 (approximately $\$ 1,400, \$ 1,730, \$ 1,450$ respectively), and they seem to accord well with other national statistics. The National Survey of Household Income and Expenditures (NSHIE), a cross-sectional household expenditure annual survey, shows that for the average household whose head is neither self-employed nor unemployed it was 1.64 million Korean won in 1995, 1.94 in 1997, and 1.82 in 1998. Family earnings in the sample are slightly larger than national statistics, in part because residents in metropolitan areas are over-sampled. In the sample, about 30 percent of households live in Seoul and about 25 percent in five big cities other than the capital city, Seoul. According to the 1995 Population Census, 23 percent of the population live in Seoul and 24.9 percent of the population live in the five other metropolitan cities. This is because young couples are more likely to live in urban areas.

Women's wage rates are generally much lower than men's, and the majority of married women in paid work are employed on a part-time basis, so it seems unusual for wives to earn as much as their husbands. The gender earnings gap in Korea is the highest of all the OECD member countries during the mid and late 1990s. Surprisingly, men's weekly working hours are about 60 - well above statutory weekly working hours. This seems 
reasonable partly because the sample includes the self-employed who usually work much longer than wage workers. However, national statistics show that the average working hours for wage and salary workers are relatively high, 50 hours per week in 1995.

On the other hand, women's working hours are very low (on average 15 hours a week), which reflects the low labor force participation of married women; in Korea, female labor force participation is the lowest of the OECD countries. It was about 48 percent in 1995 . Low female labor market participation does not seem to arise because of a high fertility rate. The average number of children in a Korean household is surprisingly low, about 1.8 - below the replacement rate, which is still consistent with other nationally representative statistics (about 1.65 children). An interesting point, which is very relevant here, is that the contrast between men and women in labor market activities may demonstrate a strong degree of specialization and division of labor within marriage between spouses.

Our crucial variable is individual spending on pocket money. In TABLE 1, we know that pocket money is not a negligible part of household expenditure. It accounts for about 12 to 15 percent of total earnings, which is slightly smaller than food and beverages (about 16 to 17 percent) and similar to education (about 11 percent, much higher than in the U.S.). It is important to note that for cultural reasons, Koreans would not consider expenditures for common interests, such as birthday gifts for children as "spending from their own pocket." It seems reasonable to assume that pocket money is the spending for individualistic personal purposes. Furthermore, a crude calculation suggests that the income elasticity of pocket money at the household level is about 0.45 , which is larger than any other item. For example, the income elasticity is about 0.24 for food and 0.36 for restaurant meals. This implies that pocket money expenditure is quite responsive to changes in earnings. Thus it makes sense to examine the decision-making process by which households change pocket money in response to earnings changes.

It is interesting to see how serious the neglect of intra-household inequality is for the measurement of general inequality. Following the approach of Haddad and Kanbur (1990), I calculate various inequality measures at both the household and individual level and compare one another. At the household level, we pretend to have only the data on total household spending of pocket money and take household averages to measure inequality. 
TABLE 2 shows the results. For every measure, inequality is significantly underestimated when we only exploit the household-level data, and the understatement is quite large, ranging from $26 \%$ to $31 \%$. The magnitude is comparable to that of Haddad and Kanbur (1990) where they use the data on individual calorie intake. The results here suggest that it is important to understand intra-household resource allocation mechanism in order to measure individual welfare and the true status of inequality and poverty in the economy.

\subsection{Are Married Couples Really Different from Singles?}

Before examining how family resources are allocated between spouses, I first test whether the predictions of the unitary model hold for singles. This is necessary because rejecting the unitary model might be a consequence of a general failure of economic theory (Lundberg and Pollak 1996). Otherwise, by definition, the unitary model must hold for singles. I follow the approach of Browning and Chiappori (1998). The key idea is that if the unitary model is correct, total income and intra-household distribution of income should not directly affect demands once total consumption is conditioned. When we regress consumption on earnings variables, there should be no independent effect of individual earnings after controlling for total consumption. An econometric problem is that total consumption is potentially endogenous; however, given that income variables such as total family income and individual members' earnings are strongly correlated with total expenditure and do not directly affect household consumption, those variables should be valid instruments for total expenditure. The validity of instrumental variables can be tested if there are over-identifying restrictions.

Another useful result can be obtained from testing for over-identifying restrictions for singles and married couples. Suppose that higher-paid jobs lead to more expenses and therefore require more spending of one's pocket money. ${ }^{16}$ This seems reasonable because pocket money - personal spending outside home - can be considered as socialization costs. Then the earnings of the husband and wife will enter the demand equations for pocket money even if we make them conditional on total expenditure and other characteristics

\footnotetext{
${ }^{16}$ Browning, Bourguignon, Chiappori, and Lechene (1994) test for whether higher-paid jobs require more expensive work clothing.
} 
such as age, education, and metropolitan residence. We can check this by comparing married couples with singles because this story applies to both groups. Technically, if this effect exists, the exclusion restriction of earnings variables should be rejected for both singles and couples.

TABLE 3 shows the results of Hansen's $J$ test for singles and married couples. I regress the natural logarithm of pocket money on total expenditure and a set of control variables. For singles I include age, education, metropolitan residence, number of other family members, and three yearly dummies. Total expenditure is treated as endogenous and is instrumented by income variables: monthly earnings and its square. For couples, I include the spouses' ages, education, number of children, metropolitan residence, and three yearly dummies. The instruments for total expenditure are the husband's and wife's monthly earnings. As a result, there is one over-identifying restriction for both singles and couples.

The results for both married men and women are not consistent with the unitary models. The over-identifying restriction is rejected at any reasonable significance level. It implies that individual earnings may directly affect couples' expenditure on pocket money. However, we cannot reject the over-identifying restriction for singles ( $p$-value of 0.4908 for men and 0.6339 for women). This shows that the data for singles are consistent with the unitary models, which predict that consumption of a specific item is determined independently of earnings after making it conditional on total expenditure.

\subsection{The Determinants of Couples' Pocket Money}

TABLE 4 presents the basic results from OLS and FE estimates of pocket money determination in equations (11) and (13). First, the OLS estimates in column (1) and (2) imply that pocket money significantly increases as one's own earnings as well as the spouse's earnings increase. Interestingly, one's pocket money is more responsive to one's own earnings than to the spouse's earnings. A husband's pocket money increases by about 26 percent in response to a unit increase in his own earnings, while it only increases by 15 percent in response to the same increase in the wife's earnings. Equality is rejected at any meaningful significance level $(p$-value $<.01)$, which puts in question the hypothesis that 
spouses pool their earnings. According to the income-pooling hypothesis, the coefficient of one's own earnings should be equal to that of the partner's earnings and total family earnings only matter in intra-household allocation if earnings are exogenous. Likewise, the wife's pocket money is also more sensitive to her own earnings than to her partner's earnings. I again reject equality at any significance level $(p$-value $<.01)$.

The OLS estimates are likely to be biased due to the endogeneity of earnings variables. As seen in the previous section, there are mainly two sources of bias: unobserved heterogeneity across households and spouse-specific unobserved decision-making power. Fortunately we can get rid of the endogeneity of earnings by exploiting transitory variation in individual earnings and differences in assignable expenditures between spouses. The results, when we take the first into account, are presented in column (3) and (4). A Hausman test rejects the null that the OLS estimates are consistent $(p$-value $<.01)$. It is notable that the coefficients decrease in magnitude across the board. Since pocket money represents expenditure for personal purposes, this unobserved fixed effect may capture the family's marginal rate of substitution between private and public consumption. ${ }^{17}$

The last two columns in TABLE 4 show the results of the estimation that includes both family-specific and spouse-specific fixed effects. Compared to the results in column (3) and (4), I find that the marginal effects of one's own earnings decrease while those of the spouse's earnings increase. These changes are consistent with the predictions that the spouse-specific fixed effect would pick up unobserved bargaining power, and it is positively correlated with earnings. The strong correlation between earnings and private consumption comes in part from their common linkages to an unobserved factor: the spouse's general decision-making power. In particular, the effect of women's earnings on men's pocket money significantly increases from almost zero to about 8 percent. This supports the argument that increases in men's decision-making power would depress women's labor market activities, if other things are equal.

TABLE 5 presents the results of estimation with a set of control variables. These

\footnotetext{
${ }^{17}$ An alternative explanation for the decreases in marginal effects of earnings when we control for familyspecific effects is consumption smoothing in the permanent-income hypothesis. This is discussed in Section 6.
} 
are: spouses' age and education, number of children, metropolitan residence, and three yearly dummies. The estimated coefficients on the earnings variables are almost equivalent to those in TABLE 4. The marginal effects of one's own earnings decrease as family heterogeneity in taste and in bargaining relations between spouses are controlled for. The marginal effects of spousal earnings increase after controlling for spouse-specific fixed effects.

The last rows in TABLE 4 and 5 test for the income-pooling hypothesis, according to which individual and spouse earnings should have the same effect on pocket money allocation if earnings are exogenous. Interestingly, we strongly reject the income-pooling hypothesis in the first two columns where unobserved bargaining power is not included, but the hypothesis cannot be rejected when unobserved decision power is controlled for. This suggests that individual earnings might not be distribution factors.

Other results are worth noting here. First, children decrease parents' personal expenses. This negative effect is expected, since the presence of children changes the household's tastes for public and private consumption and, furthermore, makes resources and budgets tighter. Interestingly, I find this negative effect only for wives. In column (5) and (6), an additional child significantly decreases the mother's pocket money by 17 percent while there is virtually no effect of children on the father's pocket money. These results are in harmony with previous findings, that mothers are generally more concerned about children than fathers are (Thomas 1990, Lundberg and Pollak 1996).

Education has positive effects on pocket money. An additional year of schooling increases an individual's pocket money by about 2-5 percent. Interestingly, education generally increases pocket money, no matter who goes to school. The results imply that higher-educated couples generally enjoy more individualistic and independent family lifestyle and that they spend more money for personal purposes.

\section{4 "Traditional" versus Dual-Earner Marriage}

Unlike Western countries, single-earner households are the most common type of household structure in Korea, even though female labor force participation has been rising and there have recently been increasing numbers of dual-income couples. In most single-earner 
households, men are the only earner, so I focus on male single-earner households only.

Investigating male-working single-earner households is interesting and useful for the purpose of this paper, because men's labor supply is almost fixed. So the endogeneity problem of earnings due to endogenous labor supply is weak. On the other hand, the disadvantage is that we cannot recover household sharing rules.

TABLE 6 shows the results for single-earner households. The results are surprisingly similar to previous findings. The OLS estimates are overall biased upward. After controlling for family-specific heterogeneity, the estimates are reduced in magnitude by half. Also consistent with previous results, unobserved bargaining power is correlated with earnings. As expected, men's earnings are positively correlated with their own power, but negatively correlated with their wives' power. Given that men's labor supply and working hours are nearly fixed, this implies that earning power, represented by the hourly wage rate, is positively correlated with within-household decision-making power. ${ }^{18}$ The endogeneity of earnings in intra-household allocation cannot be fully explained by endogenous labor supply.

\subsection{Exogenous Variation in Earnings due to the Financial Crisis of 1997- 1998}

The currency crisis that erupted in Thailand in July 1997 developed into a general financial distress in Asia. After the exchange-rate collapse of December 1997, the South Korean economy experienced the most severe recession in thirty years. Output growth plunged to $-5.8 \%$, and unemployment more than tripled.

Changes in individual earnings and subsequent changes in one's relative contribution to family income due to the economy-wide financial crisis are random as long as they are not correlated with individual characteristics. In this sense we can say that the financial crisis randomizes the income distribution across households as well as within households. TABLE 7 confirms this assumption. It compares households that suffered earnings loss

\footnotetext{
${ }^{18}$ Cooperative bargaining models imply that spouses' hourly wage rates - earning power - affect intrahousehold resource allocation because threat points are the maximal level of utility attainable outside the marriage (McElroy and Horney 1981).
} 
between 1997 and 1998 with those that did not. They are almost equivalent in age, education, and other family characteristics. ${ }^{19}$

TABLE 8 presents the results using the quasi-exogenous variation in earnings due to the financial crisis. The results are again very similar to the previous ones. The OLS results overestimate the marginal effects of earnings on pocket money expenditure. Familyspecific heterogeneity plays a significant role for both husbands and wives. The omission of unobserved bargaining power would severely bias the estimates, in particular the effects of spouse's earnings on his or her own pocket money. In column (3) and (4), where only the family-specific fixed effect is included, women's earnings have virtually no impact on men's pocket money, but the effect is significant in both magnitude and statistical sense after controlling for the spouse-specific fixed effect. On the other hand, the effect of men's earnings on women's pocket money does not change much after controlling for spouse-specific fixed effect. This indicates that men's earnings are not as important for the household's decision about women's pocket money as women's earnings are for the decision about men's pocket money.

It is also interesting that we can test for the specification of our empirical model as long as changes in relative earnings due to the financial crisis are exogenous. The idea is that if the model is correctly specified, then it must have predictive power for the changes in the dependent variable in response to exogenous changes in any explanatory variables. For this I first re-estimate the model on the sample until $1997 .{ }^{20}$ Using the estimates and sample means (TABLE 1), it is easy to get the predicted value of the dependent variable. Formally, $E\left(C_{i, 98}\right)=\bar{C}_{i, 97}+\left(\widehat{\alpha}_{i}\left(\bar{y}_{h, 98}-\bar{y}_{h, 97}\right)+\widehat{\beta}_{i}\left(\bar{y}_{w, 98}-\bar{y}_{w, 97}\right)\right)$ where the upper bar represents the sample mean of the corresponding variable. We assume that

\footnotetext{
${ }^{19}$ The significant differences are found in initial earnings before the crisis. Those who suffered negative earnings shock used to make less money. This is in part because they had lower-level jobs. The difference is larger for women because labor force participation is very low in Korea. For those who worked in 1997, the gap is smaller, but still those whose earnings decreased made less money in 1997. This indicates that negative earnings shock due to the financial crisis was more severe in absolute terms for high-income households.

${ }^{20}$ The estimates are not qualitatively different from those in TABLE 5 . The estimates are $\alpha_{h}=.092$, $\beta_{h}=.067, \alpha_{w}=.017$, and $\beta_{w}=.104$.
} 
those characteristics in $X$ did not significantly change during the crisis. The model is quite successful in prediction; the predicted value for men's pocket money in natural logarithms is 2.70 while the actual value is 2.58 . Women's pocket money is predicted as 1.76 comparable to the actual value, 1.51. One interesting finding is that the model tends to underestimate the negative effects of earnings loss on pocket money for both men and women. This is perhaps because households reduce their expenditure in general in response to severe uncertainty during the crisis. Since the economy steadily grew between 1995 and 1997, the estimates based on the data over the stable period cannot capture this additional factor in household resource allocation decisions during the crisis. ${ }^{21}$

\section{Observable Household Sharing Rules}

Having estimated the marginal effects of earnings on spouses' pocket money, we can easily recover household sharing rules up to an additive constant. The results are displayed in TABLE 9. Unlike in Section 2, I calculate $\partial(\phi / Y) / \partial \theta$ and $\partial(\phi / Y) / \partial Y$ for expositional simplicity. They indicate the marginal effects of the earnings ratio and total income on the husband's share of total income, respectively.

TABLE 9 summarizes them across specifications. Recall that the partial effects of the earnings ratio, and total earnings on household sharing rules can be consistently estimated only when both family heterogeneity and bargaining power are controlled for. First, the effect of the earnings ratio is estimated as between -.01 and -.06. The negative sign confirms the theory's prediction, but the magnitude is quite small, comparable to the finding of Browning, Bourguignon, Chiappori, and Lechene (1994).

Furthermore, our estimates based on random earnings shock during the financial crisis between 1997 and 1998 suggest that relative earnings have virtually no impact on the sharing rule. This implies that the sharing rule is somehow a long-term agreement between spouses and would not change in response to temporary changes in earnings. Dercon

\footnotetext{
${ }^{21}$ The results are also consistent with the fact that consumption must be more sensitive to unexpected shock in income. The estimates for the sample until 1997 are likely to reflect mostly the effects of expected income changes on pocket money expenditure.
} 
and Krishnan (2000) argue that Pareto-efficient collective household models should be consistent with efficient risk sharing among the members. ${ }^{22}$ Our results confirm this; we cannot reject equality, $\alpha_{h}=\alpha_{w}$ and $\beta_{h}=\beta_{w}$. Random earnings shocks due to the financial crisis do not change the between-spouse difference in inter-temporal path of pocket money expenditures. This finding is very important from a policy-making perspective. It suggests that any resource transfer among household members through temporary short-run policy measures would be ineffective in altering individual welfare. Finally, the income-pooling hypothesis cannot be rejected for both men and women: $\alpha_{h}=\beta_{h}$ and $\alpha_{w}=\beta_{w}$.

On the other hand, controlling for family-specific effects only would exaggerate the effects of the earnings ratio on sharing rules. Family fixed-effect models suggest that a 100 percent increase in the earnings ratio would lead to an 18 percent budget share transfer from the husband to the wife.

Comparison across specifications shows that the estimates of household sharing rules based on the simple OLS estimation method are not so biased (except the lowest panel where random variation in earnings are utilized for identification). This finding is encouraging because it shows that the previous estimates on cross-sectional data in the literature are not badly biased. That is because family heterogeneity and bargaining power generate opposite biases so that their effects are offset in the OLS estimates. ${ }^{23}$

Interestingly, the effects of total earnings on the sharing rules are significant. It is notable that the estimates are quite stable across the models. This indicates that the earnings effects are not so highly correlated with unobserved family heterogeneity and bargaining power. The magnitudes are quite larger when compared with the earnings ratio effects. They imply that a one dollar increase in total earnings increases the husband's budget share by about 70 cents, regardless of which spouse makes the additional dollar. This suggests that women in low-income households control a higher share of total household resources than those in high-income households. ${ }^{24}$ Increases in total household

\footnotetext{
${ }^{22}$ They show that the between-spouse difference in (calorie) consumption growth path over time does not change in response to temporary health shock.

${ }^{23}$ However, the OLS estimates are severely biased when we estimate marginal effects of individual earnings on the determination of pocket money.

${ }^{24}$ Browning, Bourguignon, Chiappori, and Lechene (1994) estimate the effect of total expenditure on the
} 
earnings worsen the wife's position within households. Intra-household inequality is worse for high-income households. This is in part consistent with the Kuznets curve at the micro level (Kanbur and Haddad 1994).

\section{Unobserved Bargaining Power and Non-Assignable Con- sumption}

From equation (14) it is possible to recover $\tilde{\theta}$ up to an increasing transformation-an increasing function of the husband's relative decision power over the wife. ${ }^{25}$ The results for the between-spouse log difference equation are presented in TABLE 10. The OLS estimation is strongly rejected by the FE specification by Hausman test.

Note that it is an empirical question whether the between-spouse differences in individual fixed effects really capture unobservable relative bargaining power. As seen in the previous section, the changes in the coefficient estimates across specifications seem to support our specification of unobservable bargaining power as an individual fixed effect. In this section we look at the relationship between "unobservable" bargaining power and other distribution factors which have conventionally been used in the literature. In particular, we try to test whether the estimated unobservable bargaining power depends on "extra-household environmental parameters," such as sex ratio in the marriage market and married women's economic opportunities in the local labor market, as suggested in cooperative bargaining models (McElroy and Horney 1981, Dercon and Krishnan 2000, Chiappori, Fortin, and Lacroix 2002).

TABLE 11 shows the results. The sex ratio is defined as the number of men per 100 wife's share in total expenditure. Given that earnings and expenditure are positively correlated to each other, their results are comparable to mine. Interestingly, contrary to my results, they find a positive effect; for example, a 60 percent increase in total expenditure increases the wife's share by about 12 percent.

${ }^{25}$ One might argue that variations in the estimated fixed effects across households capture something other than differences in unobserved bargaining power structure. Above all, one might doubt that the fixed effects could pick up systematic residuals related to individual earnings since earnings are linearly specified. However, specifying earnings variables in a quite flexible way such as allowing for polynomials and splines does not change the results. 
women between age 25-49 in the residential city or region. The results are consistent with the argument that the wife's relative position within the household depends on her economic opportunities outside the household. As women are more scarce in the marriage market or as they have a better chance to get a job, their husbands' relative bargaining power is weakened. These extra-household environmental variables are jointly significant, though marginally. The results support the notion that threat points outside the marriage influence household bargaining.

Other findings are also interesting. While spousal gaps in age and education do not matter, we find that women have more bargaining power among higher-educated couples. Interestingly, we find that the existence of other members in the household significantly changes the balance of power between spouses. If the wife lives together with her parents, her relative bargaining power increases. However, the presence of young children significantly disadvantages women.

It would be interesting to examine whether this estimated unobserved bargaining power also plays a significant role in deciding household consumption on non-assignable goods. For non-assignable goods, we only observe the sum of private consumption, $C_{j f t}=C_{h j f t}+$ $C_{w j f t}$. Private consumption is determined by household sharing rules and unobserved decision-making power. Therefore,

$$
\begin{aligned}
& C_{h j}=f_{h j}\left(\phi\left(y_{h}+y_{w}, \theta, \Delta \Theta_{f}(\tilde{\theta})\right)\right) \\
& C_{w j}=f_{w j}\left(Y-\phi\left(y_{h}+y_{w}, \theta, \Delta \Theta_{f}(\tilde{\theta})\right)\right)
\end{aligned}
$$

where I omit subscripts for family and time period for simplicity. The partial derivatives with respect to $y_{h}, y_{w}$, and $\tilde{\theta}$ are:

$$
\begin{aligned}
\alpha_{j} & =\frac{\partial C_{j}}{\partial y_{h}}=f_{w j}^{\prime}(\cdot)+\left(f_{h j}^{\prime}(\cdot)-f_{w j}^{\prime}(\cdot)\right)\left(\frac{\partial \phi}{\partial Y}+\frac{\partial \phi}{\partial \theta} \cdot \frac{\partial \theta}{\partial y_{h}}\right) \\
\beta_{j} & =\frac{\partial C_{j}}{\partial y_{w}}=f_{w j}^{\prime}(\cdot)+\left(f_{h j}^{\prime}(\cdot)-f_{w j}^{\prime}(\cdot)\right)\left(\frac{\partial \phi}{\partial Y}+\frac{\partial \phi}{\partial \theta} \cdot \frac{\partial \theta}{\partial y_{w}}\right) \\
\delta_{j} & =\frac{\partial C_{j}}{\partial \Delta \Theta_{f}}=\left(f_{h j}^{\prime}(\cdot)-f_{w j}^{\prime}(\cdot)\right) \frac{\partial \phi}{\partial \Delta \Theta_{f}}
\end{aligned}
$$


The partial derivatives across consumption items are related in a restricted way,

$$
\frac{\alpha_{j}-\beta_{j}}{\delta_{j}}=-\frac{1}{Y} \cdot \frac{\partial \phi / \partial \theta}{\partial \phi / \partial \Delta \Theta_{f}}=\frac{\alpha_{k}-\beta_{k}}{\delta_{k}},
$$

for all $j \neq k$. The restrictions across different non-assignable goods, a modified distributionfactor proportionality, are testable (Chiappori, Fortin, and Lacroix 2002, Bourguignon, Browning, and Chiappori 1995). I estimate the simultaneous determination of a set of consumption items, which are non-assignable in the data set, such as dining at home, dining out, clothing and shoes, education, housing and heating, other non-heating utilities.

$$
C_{j f t}=\alpha_{j} y_{h f t}+\beta_{j} y_{w f t}+X_{f t} \gamma_{j}+\delta_{j} \widehat{\Delta \Theta}_{f}+e_{j f t},
$$

where the correlation structure of the $e_{j f t}$ 's across different items is unrestricted. $C_{j f t}$ is average monthly expenditure on the item $j$ by family $f$ at year $t$. If we assume that earnings are exogenous conditional on unobserved bargaining power and that consumption of these items is separable from pocket money expenditure, then it is possible to estimate consistently the system of equations by using seemingly-unrelated regression methods for the pooled sample.

TABLES 12 and 13 illustrate the results. To save space, I present only the estimates of earnings and bargaining power. Unobserved bargaining power seems to have impacts on non-assignable goods that are independent of earnings effects. Controlling for unobserved bargaining power does not significantly change the other estimates. The important thing here is that we cannot reject the cross-equation restrictions $\left(\chi^{2}(7)=10.31, p\right.$-value $=$ .1715). This implies that we cannot reject the collective household model where households decide on sharing rules.

Interestingly, it is possible to identify how spouses differ in terms of marginal propensity to consume a specific item. ${ }^{26}$ Note that $\delta_{j}$ is the product of between-spouse differences in marginal propensity and the marginal effect of unobserved relative bargaining power on the sharing rule. Given that the latter is not zero, testing for the significance of non-zero

\footnotetext{
${ }^{26}$ Rasul (2003) finds that spouses have different preferences and there exists household bargaining over fertility.
} 
$\delta_{j}$ is equivalent to testing for whether spouses are really different in their preferences for a specific item. The first column in TABLE 14 shows the results. It finds that spouses differ in preferences for five out of eight items. It seems, in the sample, that they share same preferences for medical expenses, non-heating utilities, and housing and heating. For the other items, such as dining at home, clothing and shoes, and education, women would have stronger propensities to spend than men.

TABLE 14 shows another interesting result: the between-spouse differences vary by consumption items. For example, spouses differ in their preferences for clothing and shoes, and that difference is larger than that for dining at home. Surprisingly, education shows the largest gap in the propensity to consume between men and women, and clothing and shoes displays the second largest gap. Korean women are willing to spend more money on these items than men would, which is consistent with the previous findings for other developing countries that clothing and shoes are almost female-oriented goods and that women care more about children than men (Thomas 1990).

\section{An Alternative Explanation: The Permanent-Income Hy- pothesis}

There is another explanation for the changes in estimates depending on the unobserved error structure: the permanent-income hypothesis. Suppose that we estimate the following equation.

$$
C_{i f t}=\alpha_{i}^{P} y_{h f t}^{P}+\alpha_{i}^{T} y_{h f t}^{T}+\beta_{i}^{P} y_{w f t}^{P}+\beta_{i}^{T} y_{w f t}^{T}+\epsilon_{i f t},
$$

where $y_{h f t}^{P}$ and $y_{w f t}^{P}$ are husbands' and wives' permanent income and $y_{h f t}^{T}$ and $y_{w f t}^{T}$ are their transitory incomes. $\epsilon_{i f t}$ is the error term which is identically and independently distributed across individual-household-year pairs. Note that the equation does not allow for family heterogeneity nor unobserved decision-making power. Other family characteristics and time dummies are omitted for simplicity.

If we assume that permanent income is constant over the four-year sample period, then we can rewrite the above equation as the following: 


$$
C_{i f t}=\alpha_{i}^{T} y_{h f t}+\beta_{i}^{T} y_{w f t}+\left(\Delta \alpha_{i}+\Delta \beta_{i}\right) y_{f}^{P}-\Delta \beta_{i} y_{h f}^{P}-\Delta \alpha_{i} y_{w f}^{P}+\epsilon_{i f t}
$$

where $\Delta \alpha_{i}=\alpha_{i}^{P}-\alpha_{i}^{T}$ and $\Delta \beta_{i}=\beta_{i}^{P}-\beta_{i}^{T}$; and $y_{f}^{P}$ is the household's permanent income that is the sum of the spouses' permanent income. Actual income is the sum of permanent and transitory income, $y_{i f t}=y_{i f t}^{P}+y_{i f t}^{T}$. The permanent-income hypothesis implies that $\Delta \alpha_{i}>0$ and $\Delta \beta_{i}>0$. Consumption smoothing means that consumption varies more in response to changes in permanent income than to changes in transitory income (Deaton 1997).

If we regress consumption on actual income by the OLS estimation method without knowing permanent and transitory income, then the resulting estimates are biased upward since omitted permanent income is positively correlated with actual income.

The FE estimates that control for family-specific effects remove one source of bias the omission of household permanent income, $y_{f}^{P}$. Compared with the OLS estimates, this may reduce the magnitude of the estimates, as found across all specifications in this paper. Still individual permanent incomes are omitted. The FE estimates are biased downward.

TABLE 15 summarizes the predictions of the permanent-income hypothesis and compares them with those of the household model in this paper. When we compare the FE estimates allowing for family-specific effects only with those allowing for family- and individual-specific effects, the permanent-income hypothesis implies that the first approach underestimates all the earnings coefficients. On the other hand, unobserved bargaining power implies that the coefficients for one's own earnings would be overestimated, but those for the spouse's earnings would be underestimated. This comparison suggests that we cannot explain the findings in the previous sections by the permanent-income hypothesis. In particular, the permanent-income hypothesis cannot explain why the coefficients for one's own earnings would decrease when we allow for individual fixed effects.

\section{Conclusions}

Using unique longitudinal data on assignable, personal expenditures at the spouse level, this paper specifies household decisions in a fully stochastic fashion, thereby allowing 
for heterogeneity at the household level as well as unobserved spouse bargaining power within marriage. The balance of unobserved bargaining power between the spouses can be inferred from pocket money expenditures.

I find that unobserved bargaining power plays a significant role in determining intrahousehold allocations as well as individual members' labor market activities. Surprisingly, after controlling for unobservable bargaining power between spouses, there is, if any, only a small effect of relative earnings on intra-household resource allocation. In some cases, we cannot even reject the income-pooling hypothesis. The results presented in this paper suggest that the labor market activities of spouses are jointly decided through the same decision-making process that also governs household expenditures.

This study also finds that spouses differ in preferences for dining at home, clothing and shoes, and education, for which women generally have stronger propensities to spend than men. On the other hand, they share the same preferences for medical expenses, nonheating utilities, and housing and heating. The results here are consistent with previous findings in developed and developing countries.

Distributive inequality within households is embedded in the social norms, especially in developing countries where familial relationships have been until recently considered as a social responsibility rather than a private contract. This study shows that the balance of bargaining power between spouses is stable and robust to transitory changes in relative earnings. An important policy implication here is that public policies targeting the disadvantaged within households should be designed and implemented on the long-term basis. Increasing female involvement in labor market activities or income transfer from the husband to the wife do not generate a significant improvement of the wife's welfare within the household in the short run. As the economies are developed, traditional cultural values, such as patriarchy and Confucian norms in Asian countries, also change. Female involvement in the labor force is rather a consequence of the social changes in developing countries. 


\section{References}

[1] Attanasio, Orazio and Lechene, Valerie. "Tests of Income Pooling in Household Decisions." Review of Economic Dynamics, 2002, 5, pp. 720-748.

[2] Basu, Kaushik. "Gender and Say: A Model of Household Behavior with Endogenouslydetermined Balance of Power." mimeo, Department of Economics, Cornell University, January 2001.

[3] Becker, Gary. A Treatise on the Family. Enlarged Edition, Cambridge, Mass.: Harvard University Press, 1991.

[4] Bourguignon, Francois, Browning, Martin, Chiappori, Pierre-André and Lechene, Valerie. "Intra Household Allocation of Consumption: A Model and Some Evidence from French Data." Annales d'Economie et de Statistique, 1993, 29, pp. 138-156.

[5] Browning, Martin and Ciappori, Pierre-André. "Efficient Intra-Household Allocations: A General Characterization and Empirical Tests." Econometrica, November 1998, 66(6), pp. 1241-1278.

[6] Browning, Martin, Bourguignon, Francois, Chiappori, Pierre-André and Lechene, Valerie. "Income and Outcomes: A Structural Model of Intrahousehold Allocation." Journal of Political Economy, December 1993, 102(6), pp. 1067-1096.

[7] Browning, Martin and Meghir, Costas. "The Effects of Male and Female Labor Supply on Commodity Demands." Econometrica, July 1991, 59(4), pp. 925-951.

[8] Chiappori, Pierre-André. "Collective Labor Supply and Welfare." Journal of Political Economy, June 1992, 100(3), pp. 437-467.

[9] Chiappori, Pierre-André. "Rational Household Labor Supply." Econometrica, 1988, 56(1), pp. 63-90.

[10] Chiappori, Pierre-André, Fortin, Bernard and Lacroix, Guy. "Marriage Market, Divorce Legislation, and Household Labor Supply." Journal of Political Economy, 2002, 110(1), pp. 37-72. 
[11] Costa, Dora and Kahn, Matthew. "Power Couples: Change in the Locational Choice of the College Educated, 1940-1990." Quarterly Journal of Economics, 2000, 115(4), pp. 1287-1315.

[12] Deaton, Angus. The Analysis of Household Surveys: A Microeconometric Approach to Development Policy Baltimore, Johns Hopkins University Press for the World Bank, 1997.

[13] Dercon, Stefan and Krishnan, Pramila. "In Sickness and in Health: Risk Sharing within Households in Rural Ethiopia." Journal of Political Economy, August 2000, 108(4), pp. 688-727.

[14] Haddad, Lawrence and Kanbur, Ravi. "How Serious is the Neglect of Intra-Household Inequality?" Economic Journal, September 1997, 100(402), pp. 866-881.

[15] Jacobsen, Joyce P. and Rayack, Wendy L. "Do Men Whose Wives Work Really Earn Less?" American Economic Review, May 1996, 86(2), pp. 268-273.

[16] Kanbur, R and Haddad, Lawrence. "Are Better Off Households More Unequal or Less Unequal." Oxford Economic Papers, 1994, 46(3), pp. 445-458.

[17] Lundberg, Shelly. "Labor Supply of Husbands and Wives: A Simultaneous Equations Approach." Review of Economics and Statistics, 1988, pp. 224-235.

[18] Lundberg, Shelly and Pollak, Robert. "Bargaining and Distribution in Marriage." Journal of Economic Perspectives, Fall 1996, 10(4), pp. 139-158.

[19] Lundberg, Shelly and Pollak, Robert. "Separate Spheres Bargaining and the Marriage Market." Journal of Political Economy, December 1993, 100(6), pp. 988-1010.

[20] Lundberg, Shelly, Pollak, Robert and Wales, Terry. "Do Husbands and Wives Pool Resources?: Evidence from the UK Child Benefit." Journal of Human Resources, Summer 1997, pp. 463-480. 
[21] McElroy, Marjorie and Horney, Mary J. "Nah Bargained Household Decisions: Toward a Generalization of the Theory of Demand." International Economic Review, June 1981, 22, pp. 333-349.

[22] Phipps, Shelley and Burton, Murray J. "What's Mine is Yours? The Influence of Male and Female Incomes on Patterns of Household Expenditure.” working paper 92-12, Department of Economics, Dalhousie University, Halifax, Canada, 1992.

[23] Pollak, Robert. "For Better or Worse: The Roles of Power in Models of Distribution within Marriage." American Economic Review, May 1994, 84(2), pp. 148-152.

[24] Rasul, Imran. "Household Bargaining over Fertility: Theory and Evidence from Malaysia." mimeo, Department of Economics, University of Chicago, March 2003.

[25] Schultz, T. Paul. "Testing the Neoclassical Model of Family Labor Supply and Fertility." Journal of Human Resources, 1990, 25(4), pp. 599-634.

[26] Thomas, Duncan. "Intra-Household Resource Allocation: An Inferential Approach." Journal of Human Resources, Autumn 1990, 25(4), pp. 653-664.

[27] Udry, Christopher. "Gender, Agricultural Production, and the Theory of the Household." Journal of Political Economy, October 1996, 104(5), pp. 1010-1046.

[28] Ward-Batts, Jennifer. "Out of the Wallet and into the Purse: Using Micro Data to Test Income Pooling." mimeo, Department of Economics, Claremont McKenna College, May 2003. 
Table 1: Descriptive Statistics of Crucial Variables ${ }^{1}$

\begin{tabular}{lcccc}
\hline \hline & 1995 & 1996 & 1997 & 1998 \\
\hline Men: Age & 36.33 & 37.02 & 37.72 & 38.40 \\
& $(4.71)$ & $(4.85)$ & $(5.09)$ & $(5.70)$ \\
Education & 12.66 & 12.64 & 12.70 & 12.61 \\
& $(2.63)$ & $(2.64)$ & $(2.66)$ & $(2.62)$ \\
Monthly Earnings & 1.68 & 1.89 & 1.97 & 1.65 \\
Weekly Hours Worked & $(.94)$ & $(1.06)$ & $(.94)$ & $(.98)$ \\
& 60.82 & 60.03 & 58.21 & 58.67 \\
Monthly Pocket Money & $(19.98)$ & $(19.11)$ & $(18.68)$ & $(18.96)$ \\
& .20 & .21 & .21 & .17 \\
Women: Age & $(.18)$ & $(.21)$ & $(.19)$ & $(.12)$ \\
\hline Education & 32.91 & 33.65 & 34.35 & 35.06 \\
Standard deviations are displayed in parentheses. Monthly & & & & \\
money are in million Korean won. & & & & \\
Monthly Earnings & $(4.01)$ & $(4.31)$ & $(4.48)$ & $(4.96)$ \\
& 11.82 & 11.83 & 11.87 & 11.83 \\
Weekly Hours Worked & $(2.28)$ & $(2.30)$ & $(2.32)$ & $(2.27)$ \\
Motropolitan Cities & .15 & .26 & .27 & .25 \\
& $(.39)$ & $(.57)$ & $(.55)$ & $(.52)$ \\
& 15.21 & 15.26 & 16.60 & 13.88 \\
& $(28.44)$ & $(25.92)$ & $(26.89)$ & $(27.96)$ \\
& .07 & .08 & .08 & .06 \\
& $(.06)$ & $(.07)$ & $(.07)$ & $(.06)$ \\
\hline \hline
\end{tabular}


Table 2: Inequality Measures of Pocket Money ${ }^{1}$

\begin{tabular}{lccc}
\hline \hline & Households & Individuals & Underestimate \\
& $(A)$ & $(B)$ & $(1-A / B)$ \\
\hline Mean (Korean 10,000 won) & 13.53 & 13.53 & - \\
Coefficient of Variation $\left(I_{1}\right)$ & .7658 & 1.1117 & $31.12 \%$ \\
Gini Coefficient $\left(I_{2}\right)$ & .3463 & .4673 & $25.90 \%$ \\
Log Variance $\left(I_{3}\right)$ & .6421 & .9272 & $30.75 \%$ \\
Relative Mean Deviation $\left(I_{4}\right)$ & .2466 & .3486 & $29.25 \%$ \\
\hline \hline
\end{tabular}

${ }^{1}$ Let $C_{\text {ift }}$ denote monthly spending of pocket money of spouse $i$ in household $f$ at year $t$. Observation $x$ is $C_{i f t}$ at the individual level and $\frac{1}{2} \sum_{i=h, w} C_{i f t}$ at the household level. 
Table 3: Singles versus Married Men and Women, TwoStage Least Squares Estimation ${ }^{1}$

\begin{tabular}{|c|c|c|c|c|}
\hline & \multicolumn{2}{|c|}{ Single } & \multicolumn{2}{|c|}{ Married } \\
\hline & Men & Women & Men & Women \\
\hline \multirow[t]{2}{*}{ Monthly Consumption } & .5974 & .4153 & .5431 & .4539 \\
\hline & $(.1412)$ & $(.0827)$ & $(.0452)$ & $(.0418)$ \\
\hline \multirow[t]{2}{*}{ Own Age } & .0174 & .0251 & -.0031 & -.0074 \\
\hline & $(.0081)$ & $(.0079)$ & $(.0053)$ & $(.0061)$ \\
\hline \multirow[t]{2}{*}{ Own Education } & .0238 & .0333 & .0177 & .0365 \\
\hline & $(.0170)$ & $(.0161)$ & $(.0078)$ & $(.0090)$ \\
\hline \multirow[t]{2}{*}{ Number of Children } & - & - & -.0571 & -.1973 \\
\hline & & & $(.0210)$ & $(.0235)$ \\
\hline \multirow[t]{2}{*}{ Number of Family Members } & -.1695 & -.0979 & - & - \\
\hline & $(.0374)$ & $(.0296)$ & & \\
\hline Hansen's $J$ Statistic & .4750 & .2270 & 9.4120 & 23.9610 \\
\hline$p$-value & {$[.4908]$} & [.6339] & {$[.0022]$} & {$[.0000]$} \\
\hline$N=$ & 896 & 800 & 4,588 & 4,588 \\
\hline
\end{tabular}

${ }^{1}$ Robust standard errors are in parentheses, corrected for multiple observations by clustering. Yearly dummies and metropolitan residence are included for both singles and married couples. Spouse age and education are included for married couples. Instrumental variables are own earnings and its squared term for singles and own earnings and spousal earnings for couples. Monthly consumption is missing for 23 couples. 
Table 4: Earnings and Pocket Money without Controls ${ }^{1}$

\begin{tabular}{|c|c|c|c|c|c|c|}
\hline & (1) & $(2)$ & $(3)$ & (4) & $(5)$ & $(6)$ \\
\hline & Men & Women & Men & Women & Men & Women \\
\hline \multirow[t]{2}{*}{ Men: Earnings } & .2581 & .1765 & .1324 & .0508 & .1243 & .0589 \\
\hline & $(.0166)$ & $(.0186)$ & $(.0134)$ & $(.0134)$ & $(.0152)$ & $(.0152)$ \\
\hline \multirow[t]{2}{*}{ Women: Earnings } & .1512 & .3639 & -.0006 & .2120 & .0817 & .1297 \\
\hline & $(.0251)$ & $(.0302)$ & $(.0250)$ & $(.0250)$ & $(.0282)$ & $(.0282)$ \\
\hline \multirow[t]{2}{*}{ Women: Constant } & & -1.0090 & & -1.0090 & & \\
\hline & & $(.0501)$ & & $(.0324)$ & & \\
\hline$R^{2}$ & \multicolumn{2}{|c|}{.4142} & \multicolumn{2}{|c|}{.3922} & \multicolumn{2}{|c|}{.1527} \\
\hline Family Fixed Effect & No & No & Yes & $Y e s$ & $Y e s$ & Yes \\
\hline Spouse Fixed Effect & No & No & No & No & Yes & Yes \\
\hline Income Pooling & .0001 & .0000 & .0000 & .0000 & .1545 & .0180 \\
\hline
\end{tabular}

${ }^{1} 4,611$ couples. A constant and three yearly dummies are included. For column (1) and (2) robust standard errors are in parentheses, corrected for multiple observations by clustering. For testing for income pooling hypothesis, $p$-values are presented. 
Table 5: Earnings and Pocket Money with Controls ${ }^{1}$

\begin{tabular}{|c|c|c|c|c|c|c|}
\hline & (1) & (2) & (3) & (4) & (5) & (6) \\
\hline & Men & Women & Men & Women & Men & Women \\
\hline \multirow[t]{2}{*}{ Men: Earnings } & .2257 & .1366 & .1309 & .0530 & .1243 & .0595 \\
\hline & $(.0168)$ & $(.0178)$ & $(.0133)$ & $(.0133)$ & $(.0152)$ & $(.0152)$ \\
\hline \multirow[t]{2}{*}{ Age } & -.0026 & .0124 & - & - & - & - \\
\hline & $(.0052)$ & $(.0050)$ & & & & \\
\hline \multirow[t]{2}{*}{ Education } & .0217 & .0229 & - & - & - & - \\
\hline & $(.0076)$ & $(.0075)$ & & & & \\
\hline \multirow[t]{2}{*}{ Women: Earnings } & .1274 & .3225 & .0009 & .2085 & .0817 & .1277 \\
\hline & $(.0246)$ & $(.0284)$ & $(.0249)$ & $(.0249)$ & $(.0281)$ & $(.0281)$ \\
\hline \multirow[t]{2}{*}{ Age } & .0093 & .0044 & - & - & - & - \\
\hline & $(.0058)$ & $(.0057)$ & & & & \\
\hline \multirow[t]{2}{*}{ Education } & .0334 & .0497 & - & - & - & - \\
\hline & $(.0089)$ & $(.0090)$ & & & & \\
\hline \multirow[t]{2}{*}{ Number of Children } & -.0223 & -.1565 & -.0281 & -.1442 & -.0066 & -.1657 \\
\hline & $(.0198)$ & $(.0226)$ & $(.0285)$ & $(.0285)$ & $(.0352)$ & $(.0352)$ \\
\hline \multirow[t]{2}{*}{ Metropolitan } & .0975 & .0064 & .0222 & -.0660 & -.0071 & -.0367 \\
\hline & $(.0283)$ & $(.0283)$ & $(.0774)$ & $(.0774)$ & $(.0991)$ & $(.0991)$ \\
\hline$R^{2}$ & \multicolumn{2}{|c|}{.4447} & \multicolumn{2}{|c|}{.3990} & \multicolumn{2}{|c|}{.3707} \\
\hline Family Fixed Effect & No & No & $Y e s$ & $Y e s$ & $Y e s$ & $Y e s$ \\
\hline Spouse Fixed Effect & No & No & No & No & $Y e s$ & Yes \\
\hline Income Pooling & .0003 & .0000 & .0000 & .0000 & .1533 & .0224 \\
\hline
\end{tabular}

${ }^{1}$ 4,611 couples. A spouse-specific intercept, a constant, and three yearly dummies are included. For testing for income-pooling hypothesis, $p$-values are presented. 
Table 6: Single-Earner Couples ${ }^{1}$

\begin{tabular}{lcccccc}
\hline \hline & $(1)$ & $(2)$ & $(3)$ & $(4)$ & $(5)$ & $(6)$ \\
\cline { 2 - 7 } & Men & Women & Men & Women & Men & Women \\
\hline Men: Earnings & .2767 & .1978 & .1479 & .0689 & .1314 & .0853 \\
& $(.0183)$ & $(.0226)$ & $(.0162)$ & $(.0162)$ & $(.0183)$ & $(.0183)$ \\
\hline Women: Constant & & -1.0130 & & -1.0130 & & \\
& & $(.0589)$ & & $(.0388)$ & & \\
\hline$R^{2}$ & \multicolumn{2}{c}{.4444} & \multicolumn{2}{c}{.4255} & & \multicolumn{1}{c}{1381} \\
\hline Family Fixed Effect & No & No & Yes & Yes & Yes & Yes \\
Spouse Fixed Effect & No & No & No & No & Yes & Yes \\
\hline \hline
\end{tabular}

${ }^{1} 3,013$ couples. A constant and three yearly dummies are included. 
Table 7: Random Earnings Shock between 1997 and $1998^{1}$

\begin{tabular}{|c|c|c|c|c|}
\hline & Men & Men & Women & Women \\
\hline Earnings Shock & Non-negative & Negative & Non-negative & Negative \\
\hline \multirow[t]{2}{*}{ Men: Age } & 38.91 & 38.78 & 38.62 & 39.49 \\
\hline & $(5.25)$ & $(5.51)$ & $(5.11)$ & $(5.39)$ \\
\hline \multirow[t]{2}{*}{ Education } & 12.77 & 12.49 & 12.56 & 12.67 \\
\hline & $(2.64)$ & $(2.51)$ & $(2.51)$ & $(3.02)$ \\
\hline \multirow[t]{2}{*}{ Earnings } & 1.74 & 2.21 & 2.04 & 1.80 \\
\hline & $(.79)$ & $(.97)$ & $(.93)$ & $(.91)$ \\
\hline \multirow[t]{2}{*}{ Women: Age } & 35.64 & 35.40 & 35.34 & 35.93 \\
\hline & $(4.44)$ & $(4.56)$ & $(4.56)$ & $(4.39)$ \\
\hline \multirow[t]{2}{*}{ Education } & 12.00 & 11.70 & 11.82 & 11.74 \\
\hline & $(2.21)$ & $(2.32)$ & $(2.21)$ & $(2.54)$ \\
\hline \multirow[t]{2}{*}{ Earnings } & .32 & .26 & .12 & .80 \\
\hline & $(.64)$ & $(.49)$ & $(.34)$ & $(.73)$ \\
\hline \multirow[t]{2}{*}{ Number of Children } & 1.96 & 2.00 & 2.04 & 1.80 \\
\hline & $(.64)$ & $(.97)$ & $(.93)$ & $(.91)$ \\
\hline \multirow[t]{2}{*}{ Metropolitan Cities } & .51 & .57 & .55 & .55 \\
\hline & $(.50)$ & $(.50)$ & $(.50)$ & $(.50)$ \\
\hline$N=$ & 270 & 520 & 608 & 182 \\
\hline
\end{tabular}

1790 couples. Included are couples that appear in both 1997 and 1998 survey. Standard deviations are displayed in parentheses. Monthly earnings are pre-crisis earnings in 1997 and in million Korean won. 
Table 8: Exogenous Variation in Earnings and Pocket Money without Controls, 1997-1998 ${ }^{1}$

\begin{tabular}{lcccccc}
\hline \hline & $(1)$ & $(2)$ & $(3)$ & $(4)$ & $(5)$ & $(6)$ \\
\cline { 2 - 7 } & Men & Women & Men & Women & Men & Women \\
\hline Men: Earnings & .2643 & .2145 & .1437 & .0939 & .1230 & .1146 \\
& $(.0252)$ & $(.0252)$ & $(.0267)$ & $(.0267)$ & $(.0336)$ & $(.0336)$ \\
Women: Earnings & .1429 & .3982 & -.0049 & .2503 & .1138 & .1315 \\
& $(.0398)$ & $(.0386)$ & $(.0491)$ & $(.0491)$ & $(.0619)$ & $(.0619)$ \\
\hline$R^{2}$ & \multicolumn{2}{c}{.4240} & & .4042 & & .1399 \\
\hline Family Fixed Effect & No & No & Yes & Yes & Yes & Yes \\
Spouse Fixed Effect & No & No & No & No & Yes & Yes \\
Income Pooling & .0001 & .0000 & .0045 & .0028 & .8894 & .7965 \\
\hline \hline
\end{tabular}

1 2,102 couples. A spouse-specific intercept and a constant are included. For testing for income-pooling hypothesis, $p$-values are presented.

Table 9: Recovering Household Sharing Rules: Bargaining Effects and Kuznets Effects

\begin{tabular}{lcc}
\hline \hline & $\partial(\phi / Y) / \partial \theta$ & $\partial(\phi / Y) / \partial Y$ \\
\hline OLS w/o controls & -.07211 & .34988 \\
Family FE w/o controls & -.18465 & .36337 \\
Family-Spouse FE w/o controls & -.06454 & .37921 \\
\hline OLS w/ controls & -.07985 & .36823 \\
Family FE w/ controls & -.17956 & .35754 \\
Family-Spouse FE w/ controls & -.06385 & .37515 \\
\hline OLS w/ random earnings & -.06876 & .30804 \\
Family FE w/ random earnings & -.14673 & .28711 \\
Family-Spouse FE w/ random earnings & -.01141 & .31750 \\
\hline \hline
\end{tabular}


Table 10: Between-Spouse Log Difference Equations $^{1}$

\begin{tabular}{|c|c|c|}
\hline & OLS & $\mathrm{FE}$ \\
\hline \multirow[t]{2}{*}{ Men: Earnings } & .0892 & .0648 \\
\hline & $(.0216)$ & $(.0194)$ \\
\hline \multirow[t]{2}{*}{ Women: Earnings } & -.1951 & -.0461 \\
\hline & $(.0318)$ & $(.0359)$ \\
\hline$R^{2}$ & .0440 & .0274 \\
\hline Hausman Test $\chi^{2}(7)$ & 61.70 & \\
\hline$p$-value & {$[.0000]$} & \\
\hline \multicolumn{3}{|c|}{$\begin{array}{l}{ }^{1} 4,611 \text { couples. Number of children, metropolitan residence, three } \\
\text { yearly dummies, and a constant are included. For OLS, time- } \\
\text { invariant variables such as spouses' age and education are also } \\
\text { included. Robust standard errors are in parentheses, corrected } \\
\text { for multiple observations by clustering. }\end{array}$} \\
\hline
\end{tabular}


Table 11: Husbands' Unobserved Relative Bargaining Power ${ }^{1}$

\begin{tabular}{lccccc}
\hline \hline & Mean & OLS & OLS & OLS & OLS \\
\hline Age Gap & 3.38 & - & -.0159 & -.0157 & -.0099 \\
& {$[2.71]$} & & $(.0063)$ & $(.0063)$ & $(.0065)$ \\
Average Age & 33.90 & - & -.0123 & -.0122 & -.0077 \\
& {$[4.51]$} & & $(.0036)$ & $(.0036)$ & $(.0049)$ \\
Education Gap & .8232 & - & .0011 & .0011 & .0084 \\
& {$[2.09]$} & & $(.0087)$ & $(.0087)$ & $(.0086)$ \\
Average Education & 11.84 & - & -.0161 & -.0157 & -.0169 \\
& {$[2.29]$} & & $(.0081)$ & $(.0081)$ & $(.0084)$ \\
Living with Husband's Parents & .0883 & - & - & -.0032 & .0017 \\
& {$[.2694]$} & & & $(.0622)$ & $(.0573)$ \\
Living with Wife's Parents & .0044 & - & - & -.2130 & -.1967 \\
& {$[.0604]$} & & & $(.1293)$ & $(.1099)$ \\
Child under Age 7 & .5853 & - & - & - & .0799 \\
& {$[.4927]$} & & & & $(.0423)$ \\
\hline Sex Ratio (25-49) & 104.79 & -.0102 & -.0113 & -.0111 & -.0118 \\
Female LFP (\%) & {$[3.58]$} & $(.0051)$ & $(.0050)$ & $(.0051)$ & $(.0052)$ \\
Female LFP Squared/100 & 48.31 & -.2919 & -.3146 & -.3128 & -.3233 \\
& {$[2.36]$} & $(.1710)$ & $(.1682)$ & $(.1683)$ & $(.1693)$ \\
& 23.39 & .3025 & .3260 & .3241 & .3340 \\
\hline Constant & {$[2.31]$} & $(.1767)$ & $(.1738)$ & $(.1739)$ & $(.1749)$ \\
\hline
\end{tabular}

14,588 couples. Sex ratio is defined as the ratio of male to female population between age 25 and 49 in the percentage scale. Robust standard errors are in parentheses, corrected for multiple observations by clustering. $p$-values are presented for joint significance of Sex Ratio, Female LFP, and Female LFP/100. Standard deviations are in brackets. 
Table 12: Non-Assignable Goods, Seemingly Unrelated

\section{Regression $^{1}$}

\begin{tabular}{lcccc} 
Items & $y_{h}$ & $y_{w}$ & $\widehat{\Delta \Theta}_{f}$ & pseudo $R^{2}$ \\
\hline (1) Dining at Home & .0416 & .0259 & - & .0017 \\
& $(.0030)$ & $(.0052)$ & & \\
& .04197 & .0231 & -.0148 & .1750 \\
& $(.0030)$ & $(.0053)$ & $(.0047)$ & \\
\hline (2) Dining Out & .0147 & .0167 & - & .2406 \\
& $(.0011)$ & $(.0019)$ & & \\
& .0148 & .0161 & -.0030 & .2415 \\
& $(.0011)$ & $(.0020)$ & $(.0017)$ & \\
\hline (3) Clothing and Shoes & .0171 & .0228 & - & .1619 \\
& $(.0013)$ & $(.0023)$ & & \\
& .0175 & .0199 & -.0157 & .1808 \\
& $(.0013)$ & $(.0023)$ & $(.0020)$ & \\
\hline (4) Education & .0487 & .0572 & - & .2268 \\
& $(.0048)$ & $(.0083)$ & & \\
& .0495 & .0509 & -.0343 & .2331 \\
& $(.0048)$ & $(.0083)$ & $(.0074)$ & \\
\hline \hline
\end{tabular}

12,599 couples. Spouses' age and education, number of children, metropolitan residence, three yearly dummies, and a constant are included. Standard errors are not corrected for multiple observations. 
Table 13: Non-Assignable Goods, Seemingly Unrelated Regression (Continued) ${ }^{1}$

\begin{tabular}{lcccc} 
Items & $y_{h}$ & $y_{w}$ & $\widehat{\Delta \Theta}_{f}$ & pseudo $R^{2}$ \\
\hline (5) Entertainment & .0147 & .0200 & - & .1526 \\
& $(.0014)$ & $(.0024)$ & & \\
& .0149 & .0187 & -.0069 & .1557 \\
& $(.0014)$ & $(.0025)$ & $(.0022)$ & \\
\hline (6) Medical Expenses & .0069 & .0042 & - & .0246 \\
& $(.0016)$ & $(.0027)$ & & \\
& .0069 & .0040 & -.0015 & .0248 \\
& $(.0016)$ & $(.0028)$ & $(.0025)$ & \\
\hline (7) Non-Heating Utilities & .0058 & .0044 & - & .3382 \\
& $(.0007)$ & $(.0012)$ & & \\
& .0059 & .0043 & -.0009 & .3383 \\
& $(.0007)$ & $(.0013)$ & $(.0011)$ & \\
\hline (8) Housing and Heating & .0176 & .0328 & - & .0908 \\
& $(.0025)$ & $(.0043)$ & & \\
& .0175 & .0333 & .0030 & .0910 \\
& $(.0026)$ & $(.0044)$ & $(.0039)$ & \\
\hline \hline
\end{tabular}

1 2,599 couples. Spouses' age and education, number of children, metropolitan residence, three yearly dummies, and a constant are included. Standard errors are not corrected for multiple observations. 
Table 14: Testing Between-Spouse Differences in Marginal Propensity to Consume $\left(f_{h j}^{\prime}-f_{w j}^{\prime}=0, \forall j\right)$ and Their Equality Across Items $\left(f_{h j}^{\prime}-f_{w j}^{\prime}=f_{h k}^{\prime}-f_{w k}^{\prime}, \forall j \neq k\right), p$-values

\begin{tabular}{|c|c|c|c|c|c|c|c|c|}
\hline \hline Items & $f_{h j}^{\prime}=f_{w j}^{\prime}$ & $(2)$ & $(3)$ & $(4)$ & $(5)$ & $(6)$ & $(7)$ & $(8)$ \\
\hline$(1)$ & .0016 & .0160 & .8577 & .0230 & .1005 & .0122 & .0034 & .0026 \\
\hline$(2)$ & .0827 & - & .0000 & .0000 & .1331 & .6104 & .2788 & .1474 \\
\hline$(3)$ & .0000 & - & - & .0107 & .0001 & .0000 & .0000 & .0000 \\
\hline$(4)$ & .0000 & - & - & - & .0003 & .0000 & .0000 & .0000 \\
\hline$(5)$ & .0019 & - & - & - & - & .0981 & .0127 & .0168 \\
\hline$(6)$ & .5434 & - & - & - & - & - & .8113 & .3198 \\
\hline$(7)$ & .4345 & - & - & - & - & - & - & .3154 \\
\hline$(8)$ & .4351 & - & - & - & - & - & - & - \\
\hline \hline
\end{tabular}

${ }^{1}$ (1) Dining at Home, (2) Dining Out, (3) Clothing and Shoes, (4) Education, (5) Entertainment, (6) Medical Expenses, (7) Non-Heating Utilities, (8) Housing and Heating.

Table 15: The Predicted Changes in Coefficient Estimates When Allowing for Individual-Specific Fixed Effects in Different Models

\begin{tabular}{cccc}
\hline \hline Coefficients & Permanent Income & Bargaining Power & Both Together \\
\hline$\alpha_{h}$ & increase & decrease & ambiguous \\
$\beta_{w}$ & increase & decrease & ambiguous \\
$\alpha_{w}$ & increase & increase & increase \\
$\beta_{h}$ & increase & increase & increase \\
\hline \hline
\end{tabular}

